\title{
Landowning, Status and Population Growth
}

\author{
Ulla Lehmijoki \\ University of Helsinki \\ HECER and IZA
}

\author{
Tapio Palokangas \\ University of Helsinki \\ HECER, IZA and IIASA
}

Discussion Paper No. 651:2013

ISBN 978-952-10-7232-1, ISSN 1459-3696

March 4, 2013 


\section{Introduction}

The core of the Malthusian thinking is the inescapable relationship between population and land: as land is fixed but population growing, a contradiction can not be avoided (Mathus, 1798). This document shows that it is essential to know who owns the land. Land ownership creates incentives to increase the productivity of land and to limit the family size. Therefore, land reforms have often diminished population growth, in particular where land ownership generates social status and appreciation.

Lucas (2002) characterizes land-population relationship by models of human history as follows. In primitive economies, the land is commonly owned so that even altruistic parents cannot improve the lot of their descendants. Nevertheless, once land property rights are established, parents can hand the family farm over to the optimal number of children. With private ownership, a newcomer decreases income per capita so that the steady state population growth rate falls. Parents can also educate their children which increases the cost of the newcomers, decreasing the steady state population growth even further. However, the transition from high to low fertility occurs only if there is a mechanism through which modern technology can gradually replace agricultural technology (Lucas 2002). A mechanism of this kind was postulated by Galor et al. (2009): they argue that unequal land ownership discourages human capital, thus preventing the decline in population growth. Benefiting from cheap labor, the landed aristocracy retards education by its political and social status. For this reason, land reforms have triggered both modernization and demographic change.

The essential difference between Lucas (2002) and Galor et al. (2009)

is that the former focuses on the productive role of land, while the latter consider the land also as a source of social status and political power. We extend the concept of status from landowning in two ways. First, we assume that status-seeking is important not only for the landed aristocracy but also for peasants. Where the status of the peasant depends on land per capita, farming families have a strong incentive to limit their family size. Second, we show that land reforms generates modernization, i.e., a shift from high fertility and low income to low fertility and high income.

Land reforms redistribute land from the landed aristocracy to tenants. 
We model a channel from land reforms to population growth through the social status, which is characterized by land per capita in the family relative to that elsewhere in the economy. A land reform decreases population growth the more, the stronger is the desire of status. The importance of status was already recognized by Adam Smith (1776), who denoted the appreciation of productive assets as the "Spirit of Capitalism". Kurz (1968), Corneo and Jeanne (2001) and Fisher and Hof (2005) used status to explain economic growth in advanced economies. Later, Lehmijoki and Palokangas (2009, 2010) applied status-seeking to explain economic and demographic growth in developing countries.

This document is organized as follows: Section 2 considers the optimal behavior of peasant families. Section 3 examines the dynamics of the economy. Sections 4 and 5 consider the long-run and short-run effects of land reforms, illustrating the transition from high fertility and low income to low fertility and high income. Section 6 provides supporting evidence from Europe. Section 7 summarizes the results.

\section{Peasant families}

\subsection{Fertility, production and investment}

In the economy, there is one good which is chosen as the numeraire. On the assumption that the peasant families are similar, we can consider an infinitely living representative family of $L$ members which either rear children or work in the family farm. We assume that the mortality rate is zero, for simplicity, and define the population growth rate $n$ as follows:

$$
n \doteq \frac{\dot{L}}{L} \doteq \frac{1}{L} \frac{d L}{d t}
$$

where $t$ is time and $\left(^{*}\right)$ the derivative with respect to time.

There is one unit of land in the economy. The representative peasant family owns $\beta \in[0,1)$ units of land, and the non-farming landowner own the rest $1-\beta$. Because the latter does not use land in production, the peasant family hires the difference $x-\beta$ for $x>\beta$, and performs as an independent farmer for $x \leq \beta$. 
The number of family members in child rearing, $q n L$, is in fixed proportion $q$ to the number of newborns $n L$. The rest of the family, $L-q n L=(1-q n) L$, works in the family farm. Let $x$ be the amount of land in production and $A$ its productivity. The output $Y$ of the single good is produced from labor $(1-q n) L$ and efficient land $x A$ with constant returns to scale:

$$
\begin{aligned}
& Y=F((1-q n) L, x A), \quad F_{1} \doteq \frac{\partial F}{\partial[(1-q n) L]}>0, \quad F_{2} \doteq \frac{\partial F}{\partial(x A)}>0 \\
& F_{11} \doteq \frac{\partial^{2} F}{\partial[(1-q n) L]^{2}}<0, \quad F_{22} \doteq \frac{\partial F}{\partial(x A)^{2}}<0 \\
& F_{12} \doteq \frac{\partial^{2} F}{\partial[(1-q n) L] \partial(x A)}>0, \quad F \text { linearly homogeneous. }
\end{aligned}
$$

The peasant family improves the productivity of land, $A$, by investment $I$ :

$$
\dot{A} \doteq \frac{d A}{d t}=I
$$

\subsection{Utility}

We denote consumption by $C$, consumption per capita by $c \doteq C / L$ and the peasant family ownership of efficient land per capita by $a \doteq A \beta / L$. Following Razin and Ben-Zion (1975) and Becker (1991), the family derives temporary utility from the logarithms of per capita consumption $c=C / L$ and the proportion of newborns in population $n$ (= the population growth rate). In addition, the peasant family benefits from its status in the society. This is proxied by the family's efficient land per capita, $a$, relative to the average efficient land throughout all families, $\kappa$. Thus, we augment temporary utility by an increasing function $v(a-\kappa)$ of the status $a-\kappa:^{1}$

$$
u(t)=\log c+\theta \log n(t)+\varepsilon v(a(t)-\kappa(t)), \quad \theta>0, v^{\prime}>0, v^{\prime}(0)=1,
$$

where $\theta>0$ and $\varepsilon>0$ are the constant weights for children and status. The bigger $\varepsilon$, the higher desire for status due to land. The bigger $\theta$, the more children the families should like to have.

\footnotetext{
${ }^{1}$ If the measure for status, $v$, were a linearly homogeneous function of $a$ and $\kappa$, we would obtain the same results with some complication.
} 
Let the constant $\rho$ be a family's rate of time preference. Noting (1) and (4), the representative peasant family's expected utility at time $t=0$ is then

$$
\begin{aligned}
& U=\int_{0}^{\infty} u(t) e^{-\rho t} d t=\int_{0}^{\infty}[\log c+\theta \log n+\varepsilon v(a-\kappa)] e^{-\rho t} d t \\
& v^{\prime}>0, \quad v^{\prime \prime}<0, \quad v^{\prime}(0)=1, \quad \rho>0, \quad \theta>0 .
\end{aligned}
$$

\subsection{Short-run equilibrium}

The peasant family takes the rent $r$ for efficient land as given. Noting (2), its budget constraint can be written as follows:

$$
I=Y-C-r A(x-\beta)=F((1-q n) L, x A)-r A(x-\beta)-C,
$$

where $I$ is investment in the productivity of land, $Y$ income from production, and $C$ total consumption and $r A(x-\beta)$ rent. The peasant family employs land $x$ up to the level at which rent $r$ equals the marginal product of land:

$$
r=\frac{\partial Y}{\partial(x A)}=F_{2}((1-q n) L, x A) \text {. }
$$

Noting $c \doteq C / L, a=A / L,(1),(2)$ and (3), the per capita budget constraint (6) and the equilibrium condition (7) can be expressed:

$$
\begin{aligned}
\dot{a} & =\frac{\dot{A}}{L}-\frac{\dot{L}}{L} \frac{A}{L}=\frac{I}{L}-n a=F\left(1-q n, x^{*} a\right)+\left[\left(\beta-x^{*}\right) r-n\right] a-c, \\
r & =F_{2}(1-q n, x a),
\end{aligned}
$$

where, given (9) and duality, the optimal value $x^{*}$ can be taken as given.

\subsection{The maximization of utility}

The peasant family maximizes its utility (5) by choosing its fertility $n$ and consumption per labor, $c$, subject to its budget constraint (8), given rent $r$. The Hamiltonian of this maximization is given by

$$
H=\log c+\theta \log n+\epsilon v(a-\kappa)+\lambda\{F(1-q n, x a)+[(\beta-x) r-n] a-c\},
$$


where, noting (9), the co-state variable $\lambda$ evolves according to

$$
\begin{aligned}
\dot{\lambda} & =\rho \lambda-\partial H / \partial a=\left[\rho+n+(x-\beta) r-F_{2}(1-q n, x a) x\right] \lambda-\varepsilon v^{\prime}(a-\kappa) \\
& =(\rho+n-\beta r) \lambda-\varepsilon v^{\prime}(a-\kappa), \quad \lim _{t \rightarrow \infty} \lambda k e^{-\rho t}=0 .
\end{aligned}
$$

The maximization of the Hamiltonian (10) by the control variables $(c, n)$ for a given $\lambda$ yields the first-order conditions

$$
\partial H / \partial c=1 / c-\lambda=0, \quad \partial H / \partial n=\theta / n-\left(q F_{1}+a\right) \lambda=0 .
$$

Given these two equations, (2) and (5), we can replace $\lambda$ by $n$ as the co-state variable and define per capita consumption $c$ as a function of capital $k$, the fertility rate $n$ and the mortality rate $m$ as follows:

$$
\begin{aligned}
& c \doteq 1 / \lambda=z(a, n) / \theta>0, \quad z(a, n) \doteq\left[q F_{1}(1-q n, a)+a\right] n>0, \quad n>0, \\
& z_{a} \doteq \frac{\partial z}{\partial a}=(q \underbrace{F_{12}}_{+}+1) n>n>0, \quad z_{n} \doteq \frac{\partial z}{\partial n}=\frac{z}{n}-q^{2} \underbrace{F_{11}}_{-} n>0 .
\end{aligned}
$$

Inserting the function (12) into the differential equation (8), the evolution of efficient land $a$

can be defined as a function of the variables $(a, n, \beta)$ as:

$$
\dot{a}=F\left(1-q n, x^{*} a\right)+\left[\left(\beta-x^{*}\right) r-n\right] a-z(a, n) / \theta .
$$

Noting (2), (9) and (12), this function has the properties:

$$
\begin{aligned}
& \frac{\partial \dot{a}}{\partial n}=-q F_{1}-a-\frac{z_{n}}{\theta}<0, \quad \frac{\partial \dot{a}}{\partial a}=F_{2} x+(\beta-x) r-n-\frac{z_{a}}{\theta}=\beta r-n-\frac{z_{a}}{\theta} \\
& \frac{\partial \dot{a}}{\partial \beta}=r a>0 .
\end{aligned}
$$

\section{The dynamics of the economy}

Consider a competitive economy inhabited by a large number of peasant families and non-farming landowners. The demand for land in production, $x$, is equal to the supply of land in equilibrium: $x=1$. Plugging this into (9) yields the equilibrium rent

$$
r=F_{2}(1-q n, a)
$$


On the assumption that all peasant families are similar, they have the same status in equilibrium, i.e. $\kappa=a$.

Consider the evolution of the economy. Given $\kappa=a,(5),(12)$ and (15), we can transform the differential equation (11) into

$$
\begin{aligned}
& \rho+n-\beta F_{2}(1-q n, a)-\varepsilon z(a, n) / \theta=\rho+n-\beta r-\varepsilon / \lambda=\rho+n-v^{\prime}(0) \varepsilon / \lambda \\
& =\frac{\dot{\lambda}}{\lambda}=\frac{d \log \lambda}{d t}=-\frac{d}{d t} \log z(a, n)=-\frac{z_{a}}{z} \dot{a}-\frac{z_{n}}{z} \dot{n} .
\end{aligned}
$$

Thus

$$
\rho+n=\beta r+\varepsilon z(a, n) / \theta=\beta F_{2}(1-q n, a)+\varepsilon z(a, n) / \theta \quad \Leftrightarrow \quad \dot{a}=\dot{n}=0 .
$$

Rearranging terms in (16) and noting $0 \leq \beta<1,(2),(12),(14),(15)$ and (17), we obtain the change of the fertility rate, $\dot{n}$, as a function of the variables $(a, n, \beta)$,

$$
\dot{n}=\frac{z}{z_{n}}\left[\beta F_{2}(1-q n, a)+\frac{\varepsilon}{\theta} z(a, n)-n-\rho\right]-\frac{z_{a}}{z_{n}} \dot{a},
$$

with the following partial derivatives:

$$
\begin{aligned}
\left.\frac{\partial \dot{n}}{\partial a}\right|_{\dot{a}=\dot{n}=0} & =\frac{z}{z_{n}}\left(\beta F_{22}+\frac{\varepsilon}{\theta} z_{a}\right)-\frac{z_{a}}{z_{n}} \frac{\partial \dot{a}}{\partial a} \\
& =\frac{z}{z_{n}}\left(\beta F_{22}+\frac{\varepsilon}{\theta} z_{a}\right)-\frac{z_{a}}{z_{n}}(\underbrace{\beta r-n}_{=\rho-\varepsilon z / \theta}-\frac{z_{a}}{\theta}) \\
& =\frac{z}{z_{n}} \beta F_{22}+\frac{z_{a}}{z_{n}}\left(2 z \frac{\varepsilon}{\theta}+\frac{z_{a}}{\theta}-\rho\right)>0 \\
& \Leftrightarrow \frac{\varepsilon}{\theta}>\frac{1}{2 z}\left(\rho-\frac{z_{a}}{\theta}\right)-\underbrace{\frac{z}{z_{a}} \beta}_{+} \underbrace{F_{22}}_{-}, \\
\left.\frac{\partial \dot{n}}{\partial n}\right|_{\dot{a}=\dot{n}=0} & -\frac{z}{z_{n}} \beta F_{12} q+\frac{z}{z_{n}}\left(\frac{\varepsilon}{\theta} z_{n}-1\right)-\frac{z_{a}}{z_{n}} \frac{\partial \dot{a}}{\partial n} \\
& =-\frac{z}{z_{n}} \beta F_{12} q+\frac{z}{z_{n}}\left(\frac{\varepsilon}{\theta} z_{n}-1\right)+\frac{z_{a}}{z_{n}}\left(q F_{1}+a+\frac{z_{n}}{\theta}\right) \\
& =-\frac{z}{z_{n}} \beta \underbrace{F_{12} q}_{=z_{a} / n-1}+\frac{\varepsilon}{\theta} z-\underbrace{\frac{z}{z_{n}}}_{+}+\frac{z_{a}}{z_{n}}(\underbrace{q F_{1}+a}_{=z / n})+\frac{z_{a}}{\theta} \\
& =\underbrace{\frac{\varepsilon}{\theta} z}_{+}+(\underbrace{1-\beta}_{+}) \underbrace{\frac{z}{z_{n}}}_{+}(\underbrace{\left.\frac{z_{a}}{n}-1\right)}_{+}+\underbrace{\frac{z_{a}}{\theta}>0,}_{+},
\end{aligned}
$$




$$
\frac{\partial \dot{n}}{\partial \beta}=\frac{z}{z_{n}} F_{2}-\frac{z_{a}}{z_{n}} \frac{\partial \dot{a}}{\partial \beta}=\frac{z}{z_{n}} r-\frac{z_{a}}{z_{n}} \frac{\partial \dot{a}}{\partial \beta}=\frac{z}{z_{n}} r-\frac{z_{a}}{z_{n}} r a=\left(1-\frac{z_{a} a}{z}\right) \frac{z}{z_{n}} r .
$$

\section{Long run effects of a land reform}

The system (13) and (18) of efficient land per capita, $a$, and the fertility rate $n$ can be linearized in the neighborhood of the steady state $\dot{a}=\dot{n}=0$ :

$$
\left(\begin{array}{cc}
\partial \dot{a} / \partial a & \partial \dot{a} / \partial n \\
\partial \dot{n} / \partial a & \partial \dot{n} / \partial n
\end{array}\right)\left(\begin{array}{c}
d a \\
d f
\end{array}\right)+\left(\begin{array}{c}
\partial \dot{a} / \partial \beta \\
\partial \dot{n} / \partial \beta
\end{array}\right) d \beta=0
$$

If the Jacobian in this equation is negative,

$$
\mathcal{J} \doteq \frac{\partial \dot{a}}{\partial a} \frac{\partial \dot{n}}{\partial n}-\frac{\partial \dot{a}}{\partial n} \frac{\partial \dot{n}}{\partial a}<0,
$$

then the system has a saddle point: there is only one initial value of the jump variable $n$ that leads to the steady state. This is assumed to be the case in the following.

Consider now a land reform that increases the proportion of land owned by the peasant families (i.e. an increase in $\beta$ ). Noting (2), (12), (14) and (23), the steady state values $a^{*}$, and $n^{*}$ are functions of preferences concerning wealth relative to children, $\varepsilon / \theta$, and the proportion of land the peasant family owns, $\beta$. The effects of the latter can be analyzed as follows:

$$
\begin{aligned}
& \frac{\partial a^{*}}{\partial \beta}=-\frac{1}{\mathcal{J}}\left|\begin{array}{cc}
\partial \dot{a} / \partial \beta & \partial \dot{a} / \partial n \\
\partial \dot{n} / \partial \beta & \partial \dot{n} / \partial n
\end{array}\right|=-\frac{1}{\mathcal{J}}\left|\begin{array}{cc}
\partial \dot{a} / \partial \beta & \partial \dot{a} / \partial n \\
\frac{z}{z_{n}} r & -\frac{z}{z_{n}} \beta F_{12} q+\frac{z}{z_{n}}\left(\frac{\varepsilon}{\theta} z_{n}-1\right)
\end{array}\right| \\
& =-\frac{1}{\mathcal{J}}\left|\begin{array}{cc}
r a & -q F_{1}-a-\frac{z_{n}}{\theta} \\
\frac{z}{z_{n}} r & -\frac{z}{z_{n}} \beta F_{12} q+\frac{z}{z_{n}}\left(\frac{\varepsilon}{\theta} z_{n}-1\right)
\end{array}\right| \\
& =-\underbrace{\frac{r}{\mathcal{J}}}_{-} \underbrace{\frac{z}{z_{n}}}_{+}(\underbrace{a z_{n}}_{+} \frac{\varepsilon}{\theta}-a \beta F_{12} q+q F_{1}+\frac{z_{n}}{\theta})>0 \\
& \Leftrightarrow \frac{\varepsilon}{\theta}>\underbrace{\frac{1}{a z_{n}}}_{+}\left(a \beta F_{12} q-q F_{1}-\frac{z_{n}}{\theta}\right)=\underbrace{\frac{q}{z_{n}}}_{+}(\beta \underbrace{F_{12}}_{+}-\underbrace{\frac{F_{1}}{a}}_{+})-\frac{1}{a \theta}, \\
& \frac{\partial n^{*}}{\partial \beta}=-\frac{1}{\mathcal{J}}\left|\begin{array}{cc}
\partial \dot{a} / \partial a & \partial \dot{a} / \partial \beta \\
\partial \dot{n} / \partial a & \partial \dot{n} / \partial \beta
\end{array}\right|=-\frac{1}{\mathcal{J}}\left|\begin{array}{cc}
\partial \dot{a} / \partial a & \partial \dot{a} / \partial \beta \\
\frac{z}{z_{n}}\left(\beta F_{22}+\frac{\varepsilon}{\theta} z_{a}\right) & \frac{z}{z_{n}} r
\end{array}\right| \\
& =-\frac{1}{\mathcal{J}}\left|\begin{array}{cc}
-q F_{1}-a-\frac{z_{n}}{\theta} & r a \\
\frac{z}{z_{n}}\left(\beta F_{22}+\frac{\varepsilon}{\theta} z_{a}\right) & \frac{z}{z_{n}} r
\end{array}\right|
\end{aligned}
$$




$$
\begin{aligned}
& =-\underbrace{\frac{r}{\mathcal{J}}}_{-} \underbrace{\frac{z}{z_{n}}}_{+}\left[-q F_{1}-\frac{z_{n}}{\theta}-a(\beta F_{22}+\frac{\varepsilon}{\theta} \underbrace{z_{a}}_{+}+1)\right]<0 \\
& \Leftrightarrow \frac{\varepsilon}{\theta}>\frac{1}{z_{a}}[-\beta \underbrace{F_{22}}_{-}-1-\frac{1}{a}(q \underbrace{F_{1}}_{+}+\underbrace{\frac{z_{n}}{\theta}}_{+})] .
\end{aligned}
$$

From (24) and (25) it follows that

$$
\lim _{\beta \rightarrow 0} \frac{\partial a^{*}}{\partial \beta}>0, \quad \lim _{\beta \rightarrow 0} \frac{\partial n^{*}}{\partial \beta}<0, \quad \lim _{(\varepsilon / \theta) \rightarrow \infty} \frac{\partial n^{*}}{\partial \beta} / \frac{\partial a^{*}}{\partial \beta}=-\frac{z_{a}}{z_{n}} .
$$

The results (24), (25) and (26) can be rephrased as follows:

Proposition 1 In the long run, a land reform (i.e. an increase in $\beta$ ) increases efficient land per capita $a^{*}$, but decreases the population growth rate $n^{*}$ if and only if either of the following conditions hold true:

(i) The initial proportion of land owned by peasants is small enough, $\beta \rightarrow 0$.

(ii) The status-effect is strong enough for

$$
\frac{\varepsilon}{\theta}>\max \{\underbrace{\frac{q}{z_{n}}}_{+}(\underbrace{\beta F_{12}}_{+} \underbrace{-\frac{F_{1}}{a}}_{-}) \underbrace{-\frac{1}{a \theta}}_{-}, \underbrace{\frac{1}{z_{a}}}_{+}[\underbrace{-\beta F_{22}}_{+} \underbrace{-1-\frac{1}{a}\left(q F_{1}+\frac{z_{n}}{\theta}\right)}_{-}]\} .
$$

This result can be interpreted as follows. A land reform definitely increases the income of the peasant family as rent payments decrease. This increases the demand for children as these are normal goods. If the status-effect of efficient land is weak, then the income effect dominates and the number of children increases after the land reform. On the other hand, if the statuseffect is strong, then the peasant family limits its size and invests the extra income to improve the efficiency of land.

\section{Short-run effects of a land reform}

The saddle-point condition (23) is equivalent to

$$
\frac{\partial \dot{a}}{\partial a} \frac{\partial \dot{n}}{\partial n}<\frac{\partial \dot{a}}{\partial n} \frac{\partial \dot{n}}{\partial a}
$$


Noting (14), (19) and (20), this implies

$$
\frac{\partial \dot{a}}{\partial a}<\underbrace{\frac{\partial \dot{a}}{\partial n}}_{-} \underbrace{\frac{\partial \dot{n}}{\partial a}}_{+} / \underbrace{\frac{\partial \dot{n}}{\partial n}}_{+}<0 .
$$

a)

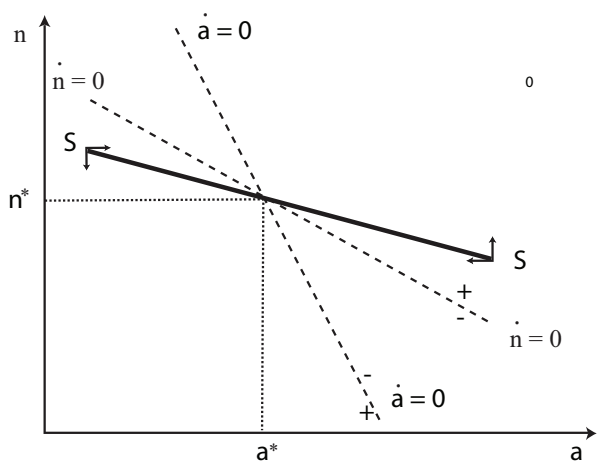

b)

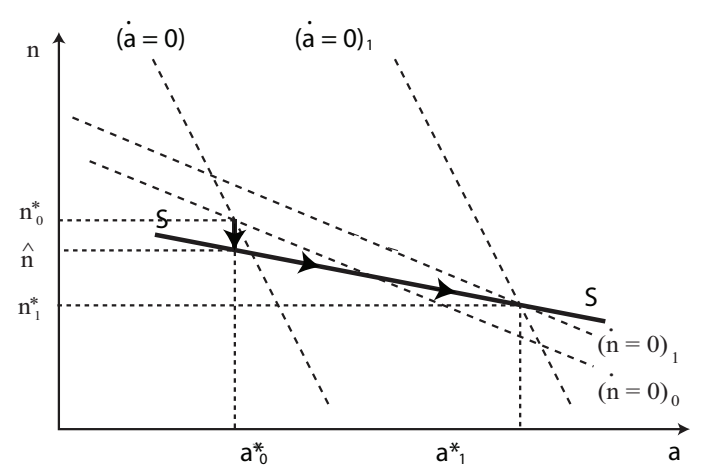

Figure 1: The phase diagram of the model.

Assume first that the system is initially in the steady state $\left(a_{0}^{*}, n_{0}^{*}\right)$. Once $\beta$ increases, the steady state moves to $\left(a_{1}^{*}, n_{1}^{*}\right)$. Given $(24)$, the status $a$ rises but the fertility rate $n$ falls, $a_{0}^{*}<a_{1}^{*}$ and $n_{0}^{*}>n_{1}^{*}$. Given (14), (20) and (27), both singular curves $(\dot{a}=0)$ and $(\dot{n}=0)$ are decreasing, but $(\dot{a}=0)$ falls more steeply: in the $(a, n)$ space:

$$
\left.\frac{\partial n}{\partial a}\right|_{\dot{a}=0}=-\frac{\partial \dot{a}}{\partial a} / \underbrace{\frac{\partial \dot{a}}{\partial n}}_{-}<-\underbrace{\frac{\partial \dot{n}}{\partial a}}_{+} / \underbrace{\frac{\partial \dot{n}}{\partial n}}_{+}=\left.\frac{\partial n}{\partial a}\right|_{\dot{n}=0}<0 .
$$

Since $\partial \dot{a} / \partial n<0$ by (14), the variable $a$ increases (decreases) below (above) the singular curve $(\dot{a}=0)$. Since $\partial \dot{n} / \partial n>0$ by $(20)$, the variable $n$ increases (decreases) above (below) the singular curve $(\dot{n}=0)$. Hence, the stable saddle path $S S$ is downward sloping (cf. Fig. 1a).

Noting (14) and (18), an increase in $\beta$ shifts both singular curves $(\dot{a}=0)$ and $(\dot{n}=0)$ upwards in the $(a, n)$ plane (cf. Fig. 1b):

$$
\left.\frac{d n}{d \beta}\right|_{\dot{n}=0}=-\underbrace{\frac{\partial \dot{n}}{\partial \beta}}_{-} / \underbrace{\frac{\partial \dot{n}}{\partial n}}_{+}>0,\left.\quad \frac{d n}{d \beta}\right|_{\dot{a}=0}=-\underbrace{\frac{\partial \dot{a}}{\partial \beta}}_{+} / \underbrace{\frac{\partial \dot{a}}{\partial a}}_{-}>0 .
$$




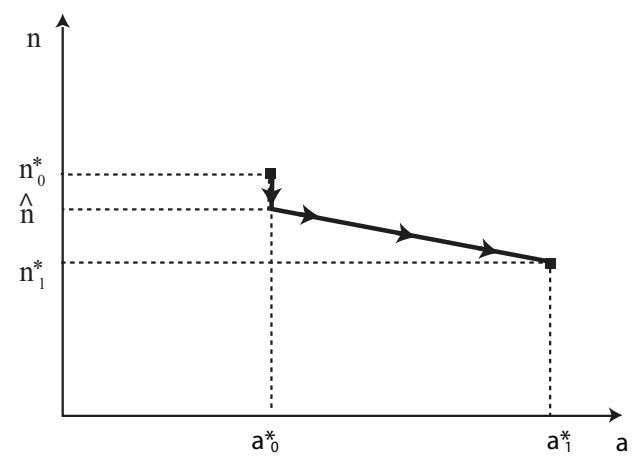

b)

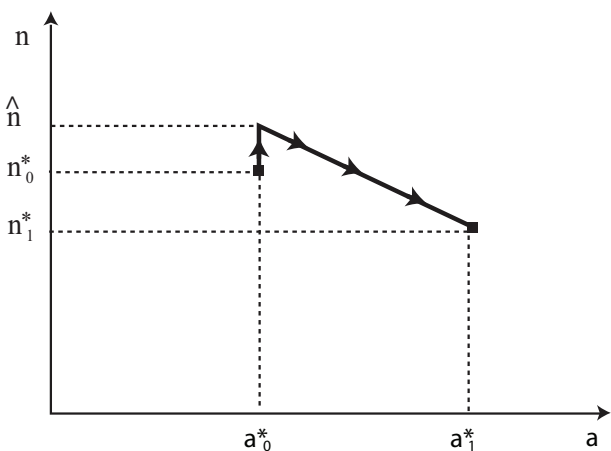

Figure 2: The development of per capita productivity $(a)$ and population growth $(n)$ after a land reform.

Figure 2 illustrates, that two types of developments are possible. In Fig. 2a, population growth undershoots. ${ }^{2}$ In this case, population growth starts to decrease immediately after the land reform. Furthermore, the initial decrease may be considerable, i.e. population growth falls drastically. Nevertheless, population growth may also adopt a reverse course in the short run (cf. Fig. $2 \mathrm{~b}$ ): it overshoots, indicating that the income effect dominates over the status effect immediately after the land reform.

Given (13), (18), (24) and (25), the population growth rate $n$ undershoots (cf. Fig. 2a), if and only if

$$
\underbrace{\frac{\partial n^{*}}{\partial \beta}}_{-} / \underbrace{\frac{\partial a^{*}}{\partial \beta}}_{+}=\frac{d n^{*}}{d a^{*}}<\underbrace{\frac{d n}{d t}}_{-} / \underbrace{\frac{d a}{d t}}_{+}<0,
$$

where $\frac{d n^{*}}{d a^{*}}$ is the slope of the line between points $\left(n_{0}, a_{0}\right)$ and $\left(n_{1}, a_{1}\right)$ and $\frac{d n}{d t} / \frac{d n}{d t}$ is the slope of the saddle path from $\left(a_{0}, \widehat{n}\right)$ to $\left(n_{1}, a_{1}\right)$. Furthermore, given (18) and (26), it holds true that

$$
\begin{aligned}
\lim _{(\varepsilon / \theta) \rightarrow \infty}\left(\frac{d n}{d t} / \frac{d a}{d t}\right) & =\underbrace{\frac{z}{z_{n}} \lim _{(\varepsilon / \theta) \rightarrow \infty}\left(\beta F_{2}+\frac{\varepsilon}{\theta} z-n-\rho\right)}_{+} / \underbrace{\frac{d a}{d t}}_{+}-\frac{z_{a}}{z_{n}} \\
& >-\frac{z_{a}}{z_{n}}=\lim _{(\varepsilon / \theta) \rightarrow \infty} \frac{\partial n^{*}}{\partial \beta} / \frac{\partial a^{*}}{\partial \beta} .
\end{aligned}
$$

\footnotetext{
${ }^{2}$ This case is illustrated in Fig. $1 \mathrm{~b}$.
} 
Thus, the inequality (30) corresponding to undershooting (cf. Fig. 2a) holds for high enough values of $\frac{\varepsilon}{\theta}$. This result can be rephrased as follows:

Proposition 2 If the status-effect (i.e. the value of $\frac{\varepsilon}{\theta}$ ) is strong enough, then the land reform (i.e. an increase in $\beta$ ) decreases the population growth rate $n$ immediately (cf. Fig. 2a).

If the status effect is very strong, then the family generates status by transferring resources from child rearing into investment in efficient land $a$.

\section{Supportive evidence}

In this Section, we provide suggestive evidence in favor of the landowning hypothesis from European history.

Cohort fertility rate (children per woman)

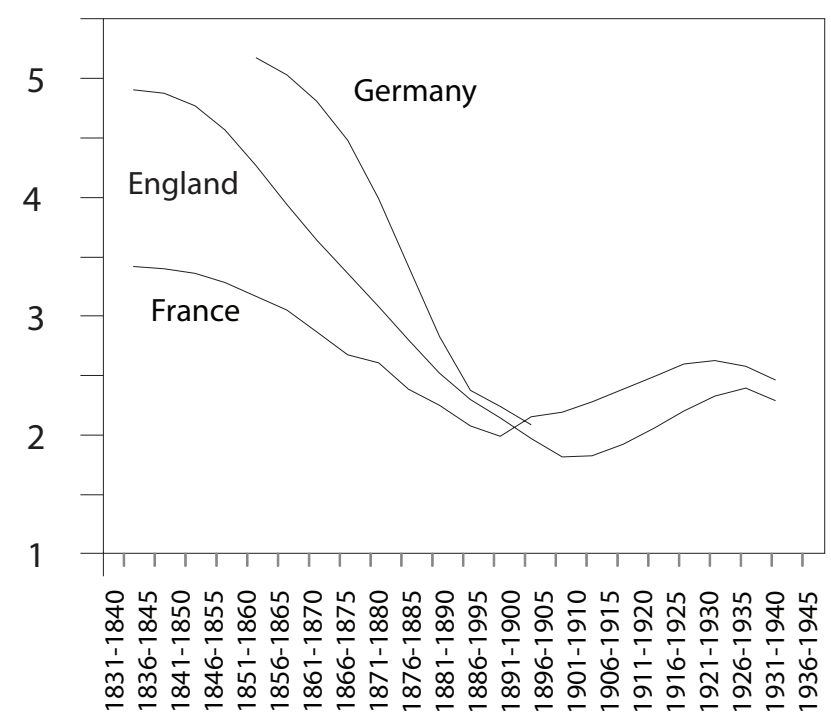

Cohort

Figure 3: The fertility decline in France, England and Germany. Source: Festy (1979, pages 266-67, 262 and 222).

One of the greatest puzzles in demographic history is why fertility declined in rich and urbanized England much later than in poor and rural France. ${ }^{3}$

\footnotetext{
${ }^{3}$ In 1820, the GDP per capita in England was 1.4 times larger than that in France, and the advantage of England only increased towards the end of the century (Maddison 1995, 194-196).
} 
Figure 3 illustrates the fertility trends in England, France, and Germany from 1831-1840 to 1936-1945, showing that even though fertility was declining everywhere, its level in 1831-1840 was much slower and its decrease much faster in France. ${ }^{4}$ If economic factors were the driving forces of the fertility decline, this should have started first in England. Nevertheless, this was not the case. In 1831-1840, the fertility in England was more than $40 \%$ higher than in France. Furthermore, it took over 30 years for England to reach the 1831-1840 numbers in France. On the other hand, England was ahead of Germany as one expected (cf. Fig. 3). Why was the fertility rate so low in France?

\section{Marital fertility rate in France}

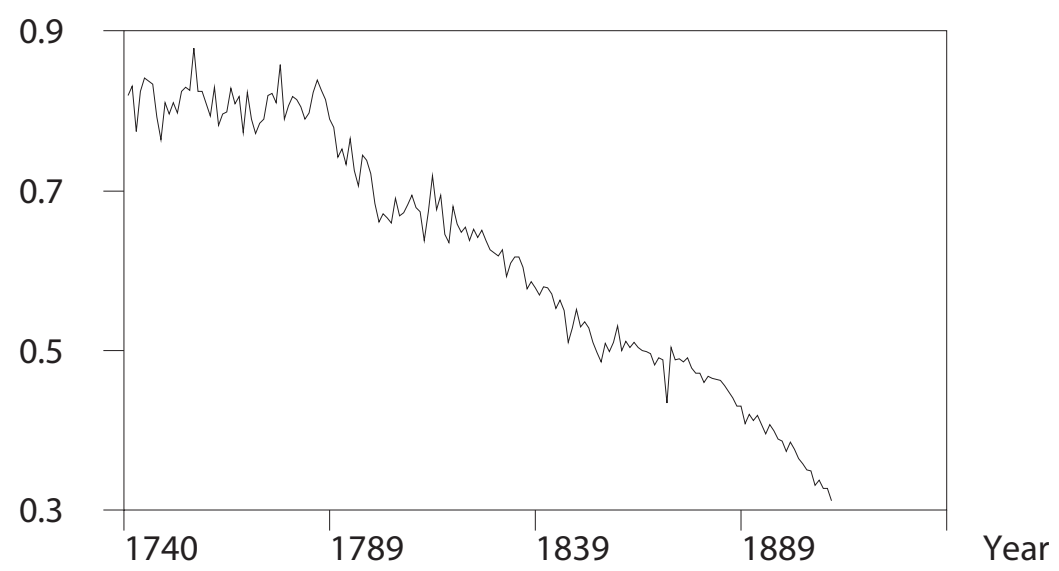

Figure 4: The marital fertility rate expressed as the share of the maximum fertility rate (1.00) in France. Source: Weir 1994.

Figure 4 presents the (marital) fertility in France from 1740 to 1911. It shows that fertility declined sharply at the time of the land reform during the Great Revolution 1789-1799, while no land reform occurred in England or Germany: in 1830, $63 \%$ of the population was landowning peasants in France, while in Britain the share of landowners was only 14\% (Chesnais 1992, p. 337). Actually, the widespread ownership of land was a unique feature of France (Gummins 2012). For the new rural bourgeoisie class, fertility control supplied a powerful method for social rise. Thus, it is likely that the fertility

\footnotetext{
${ }^{4}$ The cohort fertility rate in in Figure 3 gives the total number of births given by women born in the time period indicated in the Figure.
} 
decline in France was due to the decline in the child demand among the peasants (Gummins 2012). Furthermore, by associating early wealth and fertility data, Gummings shows that those peasants who had the greatest land property also had the lowest fertility and their fertility decline was the fastest, indicating that status-seeking may have played an important role.

Total Fertility rate in Finland and Sweden

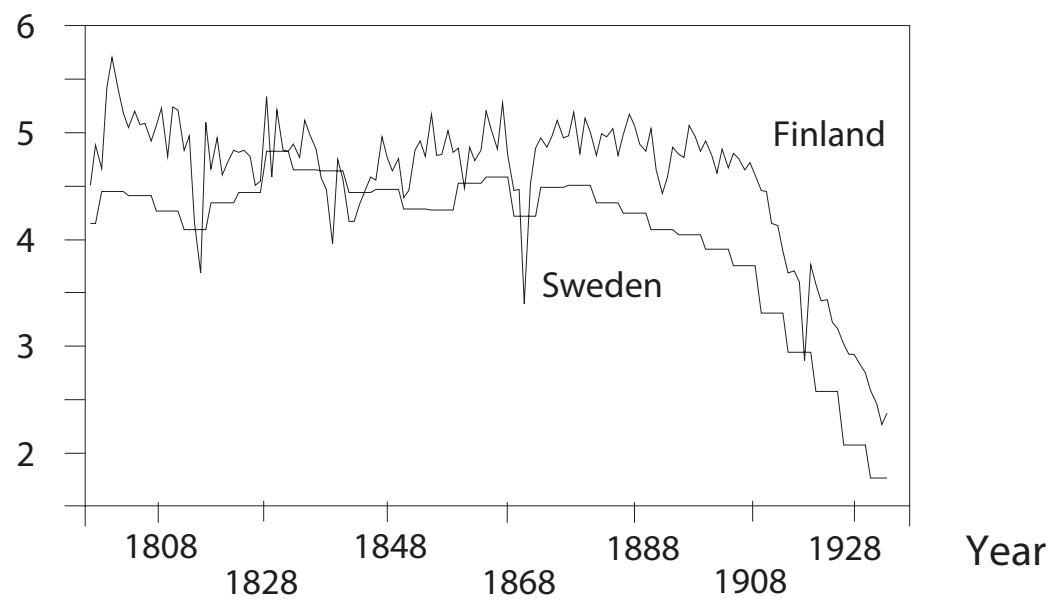

Figure 5: The total fertility rate (children per woman) from 1776 to 1935 in Finland and Sweden. Sources: Statistics Finland (2013), Statistics Sweden (2013).

Another example comes from Finland and Sweden. Finland was part of Sweden from 1150 to 1809, thus sharing many social institutions and cultural features with the latter. Figure 5 shows that, once onset, the phase of the fertility decline was fast in both countries. In Sweden, fertility decreased steadily from 1880 to 1935 , falling from 4.5 to 1.765 children per woman. In Finland, however, fertility remained high (4.72 children per woman) until 1908, but then started declining, reaching the number 2.37 in 1935 . The decline of 2.35 children in only 27 years is one of the fastest in Western countries, and may be associated with the land reform which started in 1908 as the tenants were allowed to buy their farms. ${ }^{5}$ Note that both France

\footnotetext{
${ }^{5}$ Unfortunately, the land reform experienced some drawbacks which, together with the general unrest of the time, lead to an outburst of a civil war in 1918. One of the conditions for the later social cohesion in Finland was the famous Lex Kallio (1922) which made larger and wealthier farms possible for the peasants.
} 
and Finland exhibit strong undershooting, i.e., a sudden downward jump in fertility after the land reform, indicating that the status effect may have been strong in both countries.

\section{Conclusions}

This paper examines the effects the landowning and land reforms by a familyoptimization model with endogenous fertility and status-seeking. A land reform decreases the costs of farming by decreasing the rents, generating more income for peasants. The outcome of this depends on preferences. If the role of status is small, then the peasants rear more children which are normal goods for them. This leads to persistent stagnation of income and productivity. But if the role of status is sufficient, then peasants limit their family size and invest in the productivity of land. If status-seeking is strong enough, then fertility decreases immediately after the land reform.

The demographic history in Europe provides supportive evidence for this landowning-hypothesis. Fertility declined in rich and urbanized England much later than in poor and rural France due to the land reform in the latter during Great Revolution 1789-1799. The fertility control, which supplied a powerful method for social rise for the new rural bourgeoise class, led to an exceptional fertility decline in France. There is evidence that the peasants with the greatest land property had the lowest fertility indicating they were subject to strong status-seeking. In Finland as well, the land reform in 1908 generated one of the most drastic fertility decline in Western countries.

\section{References:}

Becker Gary S. (1991): A Treatise on the Family. Enlarged Edition. Cambridge, Harvard University Press.

Chesnais, Jean-Claude (1992): The Demographic Transition: Stages, Patterns and Economic Implications. Oxford, Oxford University Press.

Corneo, Giacomo and Jeanne, Oliver (2001): On Relative-Wealth Effects and Long-Run Growth. Research in Economics 55(4), 349-358.

Festy, Patric (1979): La féconfité des pays occidentaux de 1870 à 1970. Paris, Presses Universitaires de France. 
Fisher, Walter H. and Hof, Franz X. (2005): Status Seeking in a Small Open Economy. Journal of Macroeconomics 27(2), 209-232.

Galor Oded, Weil David N. (2000): Population, Technology, and Growth: From Malthusian Stagnation to the Demographic Transition and beyond. American Economic Review 90(4), 806-826.

Galor Oded, Moav Omer and Vollrath Dietrich (2009): Inequality in Land Ownership, the Emergence of Human Capital Promoting Institutions and the Great Divergence. Review of Economic Studies 76(1), 143-179.

Guinnane, Timothy W. (2011): The Historical Fertility Transition: A Guide for Economists. Journal of Economic Literature 49(3), 589-614.

Gummins, Neil J (2012): Marital Fertility and Wealth During the Fertility Transition: Rural France, 1750-1850. Forthcoming in Economic History Review.

Kurz, Mordecai (1968): Optimal Economic Growth and Wealth Effects. International Economic Review 9(3), 348-357.

Lehmijoki, Ulla and Palokangas, Tapio (2009): Population Growth Overshooting and Trade in Developing Countries. Journal of Population Economics 22, 43-56.

Lehmijoki, Ulla and Palokangas, Tapio (2010): Trade, Population Growth, and the Environment in Developing Countries. Journal of Population Economics 23(4), 1351-1373.

Lucas Robert E. J. (2002): Lectures on Economic Growth. Cambridge, Massachusetts, Harward University Press.

Maddison, Angus (1995): Monitoring the World Economy, 1820-1992. Paris, OECD.

Malthus, Thomas R. (1798): An Essay on the Principle of Population, as it Affects the Future Improvement of Society with Remarks on the Speculations of Mr. Godwin, M. Condorcet, and Other Writers. London, Printed For J. Johnson, In St. Paul's Church-Yard.

Razin, Assaf and Ben-Zion, Uriel (1975): An Intergenerational Model of Population Growth. American Economic Review 65, 923-933.

Smith, Adam (1776): An Inquiry into the Nature and Causes of the Wealth of Nations, 1 (1 ed.). London, W. Strahan.

Statistics Finland (2013).

Statistics Sweden (2013).

Weir, David R. (1994): New Estimates of Nuptiality and Marital Fertility in France, 1740-1911. Population Studies 48(2), 307-331. 